Research report

\title{
Long-term outcomes of participants in a perinatal depression early detection program
}

\author{
Rebecca Reay ${ }^{\mathrm{a}, *}$, Stephen Matthey ${ }^{\mathrm{b}, \mathrm{c}, \mathrm{f}}$, David Ellwood ${ }^{\mathrm{d}}$, Maureen Scott ${ }^{\mathrm{e}}$ \\ a Academic Unit of Psychological Medicine, ANU Medical School, Canberra, Australia \\ b Sydney South West Area Health Service, Sydney, Australia \\ c School of Psychology, University of Sydney, Sydney, Australia \\ d Dept of Obstetrics and Gynaecology, School of Clinical Medicine, ANU Medical School, Canberra, Australia \\ e Child, Youth and Women's Health Program, ACT Health, Canberra, Australia \\ ${ }^{\mathrm{f}}$ School of Psychiatry, University of New South Wales, Sydney, Australia
}

\section{A R T I C L E I N F O}

\section{Article history:}

Received 23 February 2010

Received in revised form 30 July 2010

Accepted 30 July 2010

Available online 30 August 2010

\section{Keywords:}

Perinatal

Screening

Postnatal depression

Postpartum

Maternal bonding

Partner

\begin{abstract}
A B S T R A C T
Background: Long-term follow-up studies are required to better understand the extent of the effectiveness of early detection programs for perinatal depression. We followed up participants in such a program to investigate the long-term depression, treatment and relationship outcomes of mothers originally identified as 'probably depressed' (screened positive).

Methods: At 2 years postpartum all participants who had 'screened positive' $(\mathrm{N}=159)$ and a random sample of participants who had 'screened negative' were invited to participate in a mailed survey. Measures included: current mood; coping; access to treatment; quality of partner relationship; and mother-infant bonding.

Results: Mothers originally detected as probably depressed $(n=98)$ fared significantly worse than 'screened negative' mothers $(n=101)$ both in terms of their higher mean depression scores (EPDS: Ms $=11.0$ vs. 6.4) and greater proportions categorised as probably depressed at 2 years postpartum ( $40 \%$ vs. $11 \%$ respectively, $\mathrm{p}<.001$, phi $=.33$ ). Elevated depression symptoms at 2 years postpartum were associated with poorer partner relationships and mother-infant bonding. Moreover, there appears to be a double dose effect for women who screen positive on two occasions. Thirty-seven percent of depressed mothers did not take up treatment, frequently citing a preference for using their own resources.

Limitations: Limitations include the use of self-report measures to assess depression symptoms and mother-infant bonding. Treatment data was collected retrospectively.

Conclusions: Despite being offered treatment options, a substantial proportion of women who screened positive had poor long-term mental health and relationship outcomes. This paper discusses some of the implications for perinatal early detection and treatment programs.
\end{abstract}

(c) 2010 Elsevier B.V. All rights reserved.

\section{Introduction}

Epidemiological studies have provided substantial evidence about the high prevalence of perinatal depression and

* Corresponding author. Academic Unit of Psychological Medicine, ANU Medical School, Level 2, Building 4, The Canberra Hospital, PO Box 11, Woden ACT 2606, Australia. Tel.: +61 26244 3875, +61 418863425 (mob); fax: +61262443502.

E-mail address: Rebecca.Reay@act.gov.au (R. Reay). its adverse impacts on the mother, her partner, the family unit and the longer term emotional and cognitive development of the baby (Beck, 2001; Boath et al., 1998; Lovestone and Kumar, 1993; Murray, 1992). A significant proportion of depressed mothers go on to develop persistent or recurrent depressive symptoms (McMahon et al., 2005; Dipietro et al., 2008). For instance, between $30-60 \%$ of mothers who experience maternal depression continue to experience symptoms during the first year postpartum (Whiffen and Gotlib, 1993; Beeghly et al., 2002; Rubertsson et al., 2005) and 
$46 \%$ meet the criteria for major or subclinical depression at 2 years (Campbell et al., 1992). Research has also found that $60 \%$ of depressed mothers experience further episodes of depression between 18 months and 5 years postpartum (Cooper and Murray, 1995). Moreover, chronic depressions, lasting a year or more, have been associated with a trajectory of negative outcomes for the developing infant (Philipps and O'Hara, 1991; Campbell and Cohn, 1997; Tronick and Weinberg, 1997; Beeghly et al., 2002; Cornish et al., 2006).

In Australia, the National beyondblue Postnatal Depression Program was implemented to assist health professionals in the early detection and treatment of affected mothers (Buist et al., 2005, 2006, 2008). Such programs have demonstrated that they result in improved detection rates (Evins et al., 2000) and that widespread screening is both feasible and acceptable to consumers and health professionals (Buist et al., 2006). However, screening programs have attracted controversy due to low uptake rates and high drop-out rates (Shakespeare, 2002; Armstrong and Small, 2007), especially as women who drop-out of such programs are likely to be more severely depressed, potentially resulting in unrealistically positive evaluations (Campbell and Cohn, 1997; Heron et al., 2004; Austin et al., 2005). On the one hand, a recent study found that an integrated primary care screening, diagnosis and psychological treatment program (delivered by trained health visitors) was somewhat effective at treating depressive symptoms at six and 12 months postpartum (Morrell et al., 2009a,b). Other research into screening programs has not been so favourable (Paulden et al., 2009; Yonkers et al., 2009), with limited evidence that they improve maternal or infant outcomes in the short-term (Hewitt and Gilbody, 2009). Furthermore, the types of outcomes investigated have been criticised for being too limited whilst the long-term health outcomes go largely underreported (Webster et al., 2003; Hewitt and Gilbody, 2009).

It is also well documented that a proportion of women who are detected as depressed do not seek help or decline referral, with estimates ranging from 41 to $87 \%$ (Thio et al., 2006; Brooks et al., 2009; Smith et al., 2009; Woolhouse et al., 2009). Research into factors which deter women from seeking help have highlighted the role of stigma, system barriers, time constraints and women's preference for dealing with their own issues (Dennis and Chung-Lee, 2006; BakerEriczen et al., 2008; Chew-Graham et al., 2009; Smith et al., 2009; Woolhouse et al., 2009; Kim et al., 2010). Further research is needed to understand the extent to which different obstacles to treatment and support play a role in screening programs. Examples include: individual obstacles (fear of stigma, difficulty acknowledging problems and preference for own approaches); practical obstacles (no childcare, transport); and systemic obstacles (unaware of services, aware but unable to access them).

Taking these findings together, further long-term followup studies are required to better understand the extent of the effectiveness of widespread screening programs. In light of this, we conducted a two-year follow-up of participants in the Australian Capital Territory (ACT), one of the seven pilot sites for the National beyondblue program. Our aim was to compare the long-term health outcomes of women who were identified as 'probably depressed' in the perinatal period with mothers who were identified as 'unlikely to be depressed.'
We extended our examination of health outcomes to include the impact of depression on relationships. Furthermore, we investigated their uptake of treatment, perceived helpfulness as well as obstacles to help and support over the two-year period. As service uptake may be related to whether a woman considers she is distressed, we also included a measure to assess this variable.

\subsection{Results of original beyondblue PND research}

The present study was part of a larger public health initiative introducing routine perinatal mental health screening in Australia (Buist et al., 2005, 2008). At the commencement of the research in 2003, all hospitals in the ACT were invited to participate. Two public hospitals and one private hospital agreed to be involved in the research. The other private hospital declined citing practical barriers to recruitment. From April to December 2004, 984 women from the ACT participated in the National beyondblue Postnatal Depression Program and were assessed for symptoms of depression in pregnancy and at 6-8 weeks postpartum. It was estimated that $71.5 \%$ of the eligible population participated. Symptoms of depression were assessed using the Edinburgh Depression Scale (EPDS; Cox et al., 1987).

Women who scored 13 or more, either antenatally or 68 weeks postnatally, were classified as 'screened positive' for probable major depression. Those scoring 12 or less at both time points were classified as 'screened negative.' Specifically, of the 984 participants in the original study, 126 women (12.8\%) screened positive for depression during their pregnancy (Time 1; Mean weeks pregnant: 28.5). Of the 714 women who completed an EPDS at 6-8 weeks postpartum (Time 2), 61 women (8.5\%) screened positive. Twenty-eight women (3.9\%) screened positive at both time points. This resulted in 159 women screening positive at Time 1 and/or Time 2. All women who screened positive discussed the findings with their health professional and were provided with a beyondblue information booklet which detailed treatment and support services in the ACT. These mothers were also given a letter to take to their general practitioner whose role was to assess and diagnose mental health problems and offer options for treatment.

\section{Methods}

\subsection{Participants}

In the second postpartum year all participants who had screened positive $(n=159)$ and a random sample (every 5 th subject) of an equal number of participants who had screened negative were invited to participate in this follow-up study. Potential participants were sent a letter of invitation, a consumer information sheet on the follow-up study and informed that a research officer would contact them by telephone, inviting them to participate. Responders were sent a questionnaire package and two consent forms, one to send to the researchers and one to keep. Follow-up phone calls were undertaken after 2 weeks to encourage participants to complete and return the questionnaire packages. Fig. 1 illustrates the participant flowchart. 


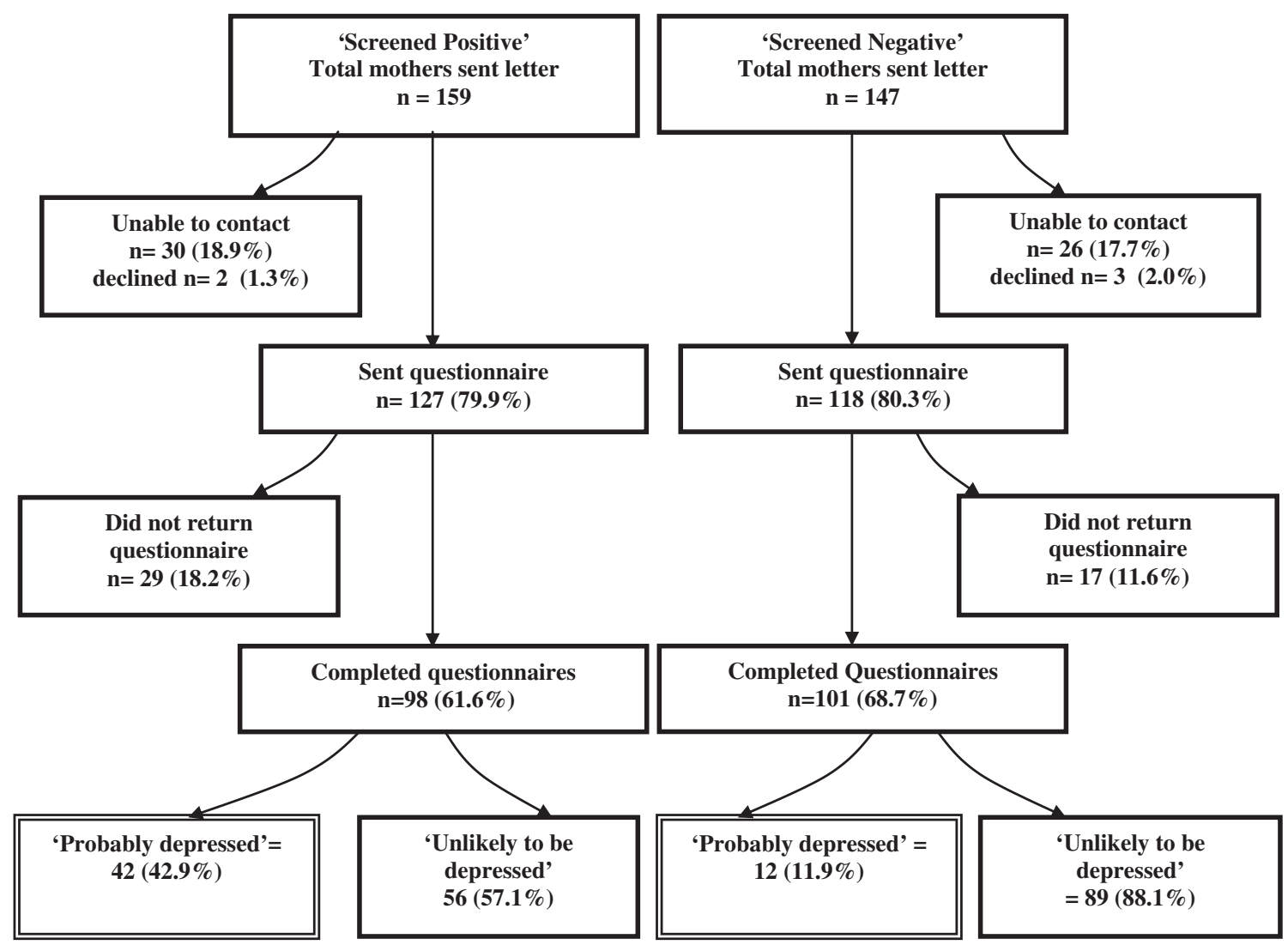

Fig. 1. Flow chart of recruitment for two-year follow-up study.

\subsection{Ethical considerations}

This study was approved by the ACT Human Health and Research Ethics Committee. Prior to administration of the questionnaire package, women were given verbal and written information on the purpose of the study. Women who returned depression scores in the symptomatic range or endorsed Question 10 on the Edinburgh Depression Scale, indicating thoughts of self harm, were contacted by the chief investigator.

\subsection{Measures}

We included measures of demographics, current mood and coping; relationships with infant and partner; and service utilization.

\subsubsection{Demographic measures}

The demographics questionnaire used in the original study was amended to capture recent changes to personal and obstetric histories, such as, pregnancies, miscarriages, births and changes in marital status or employment.

\subsubsection{Current mood and coping}

i) Edinburgh Depression Scale (EPDS; Cox et al., 1987) This is a brief (10-item), well validated measure specifically for use during the perinatal period, enquiring about mood in the past seven days. It has also been used with women outside the perinatal period
(Cox et al., 1996; Rubertsson et al., 2005; Monti et al., 2008). Scores range from 0 to 30 . It has good psychometric properties (Cox et al., 1987, 1996) and the optimum score to screen for probable major depression in English-speaking postpartum women has been shown to be 13 or more. However, around $50 \%$ of women scoring 13 or more will not have a major depression (positive predictive value $=\sim 50 \%$ ).

ii) Beck Depression Inventory, 2nd Edition (BDI-II; Beck et al., 1996)

This is a well validated, 21-item self-report measure of depressive symptomatology (over the past 2 weeks) that is widely used in perinatal populations (O'Hara et al., 1984; Milgrom et al., 2005). It has good psychometric properties (Beck et al., 1988; Beck and Gable, 2001). Scores range from 0 to 63 , with higher scores indicating more severe depressive symptoms. Scores are classified into clinical ranges of differing severity: 0-13: minimal depression; 14-19: mild depression; 20-28: moderate depression; and 29-63: severe depression (Beck et al., 1996). The BDI-II covers a wider range of depressive symptoms than the EPDS, and also covers a longer time period, and thus differences may be evident on these two measures.

iii) Reasons for Postnatal Distress Checklist - Brief version (RPDC-b; Matthey, 2009)

This recently developed self-report measure has good psychometric properties and is suitable for parents of 
infants and toddlers. This paper reports on the findings from section A which asks if the participant has had difficulty coping, or felt very stressed or very unhappy since their baby was born. The participant specifies the duration of these difficulties and the age of her infant at each time.

\subsubsection{Relationship variables}

Maternal Attachment Inventory (MAI; Muller, 1994). This 26-item scale asks respondents to indicate how they generally feel in relation to thoughts, feelings, and situations with their infant. Items are summed to create a total score that ranges from 26 to 104 . Higher scores denote greater feelings of bonding towards the infant. The MAI has been shown to have adequate internal consistency (coefficient alpha $=0.76$ ). The quality of the partner relationship was examined using a one-item question: 'How would you rate the quality of your relationship with your partner?' A five-point scale was used: $1=$ very good, $2=$ good, $3=$ so-so, $4=$ poor, $5=$ very poor. Responses were further dichotomised into either 'good relationship' (responses 1 and 2) or 'poor relationship' (responses 3-5). Mothers without partners were not included in this analysis. Information on whether women had separated or divorced since the first screening assessment was also collected to assess differences in relationship stability between the two groups.

\subsubsection{Service utilization}

Emotional Health: Treatment Access and Barriers Questionnaire (adapted from CM-IPT Treatment Life Interview Study, University of Iowa, with permission from the authors). The questionnaire asks details about various pharmacological, psychological, self help and complementary treatments; the type of health professional providing the intervention; the time period and their satisfaction with treatment received.

\subsection{Statistical analysis}

SPSS for Windows (Version 16) was used for all analyses. A series of independent t-tests were employed to examine the differences between the two groups in relation to the major study variables. Mothers with two-year EPDS scores of 12 or less were classified as 'unlikely to be depressed' and 13 or more as 'probably depressed.' This yielded a dichotomous variable which was analysed using chi-square. Analyses also included relative risk calculations for subsequent difficulty coping; descriptive analyses regarding rates of access to, helpfulness and reported barriers to treatment; comparative/ association analyses (e.g. chi-squared statistic) re: prior history of mood difficulty and post-birth difficulty coping. Effects sizes are also reported as these are considered more clinically meaningful than $p$ values (Kline, 2004). We used phi $(\phi)$ values of .15 and above and Cohen's d values of 0.4 and above as being indicative of clinical significance.

\section{Results}

\subsection{Participant flow}

Fig. 1 illustrates the flow of participants in the study. Of the 159 women who screened positive for probably depressed on the EPDS antenatally (Time 1) or postnatally (Time 2), complete data were obtained from 98 women (61.6\%). Of the non respondents, 29 (18.2\%) agreed to participate but did not return data, 30 (18.9\%) women could not be contacted by phone and two (1.3\%) declined to participate. Reasons for declining included recent miscarriage $(n=1)$ and recent birth of baby $(n=1)$. In terms of the responders who screened positive during the original study: 41 screened positive just antenatally, 20 screened positive just postnatally and 14 screened positive both antenatally and postnatally. A further 23 mothers returned a high score on their antenatal EPDS, but did not complete a postnatal EPDS. 147 women who screened negative were also invited to participate, of which 101 provided complete data (68.7\%). Twenty-six of the invited women could not be contacted by phone, 17 did not return data and three declined. Thus, the final sample comprised 98 'screened positive' women and 101 women who had originally 'screened negative.'

\subsection{Sample characteristics}

There were no differences in baseline EPDS scores or demographic variables for screened positive responders and non responders, confirming that mothers retained in the two-year sample were representative of the original sample. Overall, the mean age of women in the follow-up study was 32.3 years $(S D=5.1)$ and the mean age of their infants was 2.6 years $(S D=0.1)$. Table 1 shows the demographic data for the participants. The screened positive and negative groups were equivalent on all variables (effect sizes were not clinically significant) except for the following: mothers who screened positive were statistically significantly younger (31.1 vs. 33.5 years) and had younger infants (2.5 vs. 2.7 months). There was also a significant difference between the two groups in terms of their marital and employment status with screened positive mothers less likely to be married (80.6\% vs. $96.0 \%$ ) and less likely to be employed at 2 years postpartum $(58.2 \%$ vs. $75.2 \%)$.

\subsection{Probable depression outcomes}

Screened positive and screened negative mothers were compared in terms of mean depression scores and the proportions of women who met criteria for probable depression at 2 years. The mean two-year EPDS and BDI-II scores for mothers who screened positive in the original study were statistically and clinically significantly greater than for mothers who originally screened negative (EPDS: $M s=11.0$ vs. $6.4, p<.001, d=0.86$; BDI-II: $M s=15.9$ vs. 8.1 , $p<.001, d=0.83)$. Furthermore, from the EPDS and BDI-II results, Table 2 shows a clinically meaningful difference between the proportions of screened positive and screened negative women who were 'probably depressed' at 2 years postpartum (respective proportions: $40 \%$ vs. 11\%; $p<.001$; $\phi=.33)$. Screening positive at either Time 1 or Time 2 resulted in women having about a 1 in 2.5 chance of scoring in the clinical range (or not coping) at 2 years postpartum, as opposed to about a 1 in 10 chance for women originally screening negative. Thus, there is about a four times greater chance of scoring high at 2 years postpartum if women had screened positive antenatally or early postnatally $(R R=4.02$; 
Table 1

Comparison of two-year demographic characteristics for mothers who 'screened positive' and 'screened negative' during original study.

\begin{tabular}{|c|c|c|c|c|}
\hline \multirow[t]{3}{*}{ Variable } & \multirow{3}{*}{$\frac{\frac{\text { Screened positive }}{(\mathrm{N}=98)}}{\text { Mean }(\mathrm{SD})}$} & \multirow{3}{*}{$\frac{\frac{\text { Screened negative }}{(\mathrm{N}=101)}}{\text { Mean }(\mathrm{SD})}$} & \multirow[t]{3}{*}{$t(\mathrm{df})$} & \multirow[t]{3}{*}{$p$ (effect size) } \\
\hline & & & & \\
\hline & & & & \\
\hline Age of mother (years) & $31.1(5.5)$ & $33.5(4.4)$ & $-3.447(186)$ & $0.001(d=0.49)$ \\
\hline Range: & $20-42$ & $20-41$ & & \\
\hline Age of infant (years) & $2.54(0.2)$ & $2.66(0.2)$ & $-3.839(197)$ & $0.000(\mathrm{~d}=0.55)$ \\
\hline \multirow[t]{2}{*}{ No. of children } & 2.0 & 1.9 & 0.80 & $0.42(\mathrm{~ns})$ \\
\hline & $\%$ & $\%$ & $X^{2}(\mathrm{df})$ & $p$ (effect size) \\
\hline Primiparous (\% yes) ${ }^{a}$ & 35.4 & 31.7 & $1.07(1)$ & $0.59(\phi=.04)$ \\
\hline Marital status & & & $11.97(2)$ & $<.001(\phi=.24)$ \\
\hline Married/defacto & 80.6 & 96.0 & & \\
\hline Separated/divorced & 9.2 & 1.0 & & \\
\hline Single & 10.2 & 3.0 & & \\
\hline Currently pregnant & 12.5 & 9.0 & $0.63(1)$ & 0.49 \\
\hline Gave birth during $\mathrm{f} / \mathrm{u}$ & 23.5 & 35.6 & $3.53(1)$ & $0.06(\phi=.13)$ \\
\hline Miscarried during $\mathrm{f} / \mathrm{u}$ & 16.3 & 13.9 & $0.24(1)$ & 0.69 \\
\hline Ethnicity $^{\mathrm{a}}$ & & & $1.167(4)$ & 0.88 \\
\hline Australian & 83.7 & 87.1 & & \\
\hline Asia & 6.1 & 3.0 & & \\
\hline New Zealand/Oceania & 3.1 & 3.0 & & \\
\hline Europe and America & 5.1 & 5.0 & & \\
\hline Africa/Middle east & 2.0 & 2.0 & & \\
\hline Education $^{\mathrm{a}}$ & & & $6.523(4)$ & 0.16 \\
\hline Postgraduate degree & 6.2 & 7.9 & & \\
\hline Bachelor degree/grad dip & 22.9 & 38.6 & & \\
\hline Certificate/diploma level & 28.1 & 21.8 & & \\
\hline High school (yr7-12) & 38.5 & 28.7 & & \\
\hline Did not finish school & 4.2 & 3.0 & & \\
\hline Employment (\%Yes) & 58.2 & 75.2 & $6.55(1)$ & $0.01(\phi=.18)$ \\
\hline Type employment & & & $2.06(2)$ & 0.36 \\
\hline Full time & 21.4 & 23.7 & & \\
\hline Part time & 66.1 & 55.3 & & \\
\hline Maternity leave & 12.5 & 21.1 & & \\
\hline Mothers' occupation $^{\text {a }}$ & & & $5.99(4)$ & 0.20 \\
\hline Managers and administrators & 8.4 & 11.1 & & \\
\hline Professional & 27.4 & 34.3 & & \\
\hline Secretarial/Admin/personal services/clerical & 44.2 & 41.4 & & \\
\hline Tradesperson and related & 3.2 & 6.1 & & \\
\hline Student, unemployed, home duties & 16.8 & 7.1 & & \\
\hline
\end{tabular}

a Denotes baseline data; all other variables collected at two-year follow-up.

95\% $\mathrm{CI}=2.13-7.60)$. While the numbers are small, Table 3 shows the relationship between the number of positive screening occasions and two-year probable depression status. There is a possible dose effect for mood in the early perinatal period, with women who screened positive on both perinatal occasions more likely to be probably depressed, or to report they were not coping at 2 years, than women who screened positive on just one perinatal occasion ( $R R=1.87 ; 95 \%$ $\mathrm{CI}=1.11-3.15)$.

Examination of symptom severity using BDI-II classifications revealed $15.3 \%$ of screened positive mothers were in the

Table 3

Relationship between number of positive screening occasions and two-year depression outcome.

\begin{tabular}{|c|c|c|}
\hline \multirow{2}{*}{$\begin{array}{l}\text { Original study } \\
\text { Depression category }\end{array}$} & \multicolumn{2}{|c|}{$\begin{array}{l}\text { Two-year } \\
\text { 'probably } \\
\text { depressed' } \\
(\mathrm{N}=54)\end{array}$} \\
\hline & $\mathrm{N}$ & $\%$ \\
\hline Not depressed $n=101$ & 12 & $11.9 \%$ \\
\hline Just antenatal depression $n=41$ & 15 & $36.6 \%$ \\
\hline Just postnatal depression $n=20$ & 6 & $30.0 \%$ \\
\hline Both antenatal and postnatal depression $n=14$ & 9 & $64.3 \%$ \\
\hline Antenatal depression (missing postnatal data) $n=23$ & 12 & $52.2 \%$ \\
\hline
\end{tabular}

Table 2

Mean depression scores and proportions of women classified as 'probably depressed' or 'not coping' at two-year follow-up.

\begin{tabular}{|c|c|c|c|}
\hline & $\begin{array}{l}\text { Screened } \\
\text { positive }\end{array}$ & $\begin{array}{l}\text { Screened } \\
\text { negative }\end{array}$ & $\begin{array}{l}p \text {; effect size; relative } \\
\text { risk }(95 \% \mathrm{CI})\end{array}$ \\
\hline EDS $(\mathrm{x} ; \mathrm{SD})$ & $11.0(6.1)$ & $6.4(4.6)$ & $p<.001 ; d=0.87$ \\
\hline$\%$ in clinical range & $42.9 \%$ & $11.9 \%$ & $\begin{array}{l}p<.001 ; \phi=.35 \\
R R=3.61(2.02-6.43)\end{array}$ \\
\hline BDI-II (x; SD) & $15.9(11.0)$ & $8.1(7.4)$ & $p<.001 ; d=0.83$ \\
\hline $\begin{array}{l}\% \text { in moderate or } \\
\text { above clinical range }\end{array}$ & $35.7 \%$ & $9.9 \%$ & $\begin{array}{l}p<.001 ; \phi=.31 ; \\
R R=3.61(1.89-6.88)\end{array}$ \\
\hline $\begin{array}{l}\text { Currently not coping } \\
\text { (RPDC-b) }\end{array}$ & $28 \%$ & $13.8 \%$ & $\begin{array}{l}p=.017 ; \phi=.17 \\
R R=1.99(1.11-3.56)\end{array}$ \\
\hline
\end{tabular}

EDS = Edinburgh Depression Scale; BDI-II = Beck Depression Inventory-II; $\mathrm{RPDC}-\mathrm{b}=$ Reasons for Postnatal Distress Checklist - Brief version. 
mild range whilst $35.7 \%$ were classified in the moderate to severe range at 2 years. Of the screened negative mothers: $11.9 \%$ were classified as having mild symptoms and $9.9 \%$ were in the moderate to severe range. Thus the relative risk of having moderate-severe, as opposed to minimal or mild, depressive symptomatology for screened positive women was 3.60 (95\% CI=1.95-6.89). Table 4 shows that the proportion of women from both groups (screened positive vs. screened negative) who report on the RPDC-b that they have had difficulty coping for 2 weeks or more since the birth was similar (34\% vs. $23.8 \%$, respectively; $p=.11, \phi=.11$ ). Approximately two-thirds of these women in each screening category report that the onset of their first period of difficulty coping was within the first 3 months postpartum. In sum, a significant number of women who reported difficulties coping, feeling stressed or unhappy for 2 weeks or more in the early postpartum were not detected by the original screening program.

\subsection{Access to treatment and obstacles to care}

Not surprisingly, the screened positive women were significantly more likely to have received treatment in the 2 years since the birth ( 63.3 vs. $21.8 \% ; \chi^{2}[1, N=199]=35.09$, $p<.001, \phi=.42$ ). There was no apparent dosage-type effect of receiving treatment and this being related to whether a woman was probably depressed on one or both screening occasions. Even after controlling for baseline depression scores, there was no statistical or meaningful difference between screened positive mothers who received treatment $(n=62)$ or did not received treatment $(n=36)$ and their mean EPDS depression scores $(F(2,97)=.002, p=.96)$ or proportions classified as probably depressed (45.2\% vs. $38.9 \%)$. Respective means at 2 years postpartum were: EPDS: 11.1 and 11.0; BDI-II: 16.1 and 15.8. In terms of the professionals they consulted, many women (29.6\%) received a combination of treatment from specialist mental health professionals and medical/nursing professionals, $25.5 \%$ received treatment from medical and nursing professionals only, whilst fewer received their treatment from specialist mental health professionals only (7.1\%). Only one woman reported that she received treatment from a complementary therapist alone. Table 5 details the treatment, help and support received. Half to three-quarters of women reported each professional treatment to be helpful or very helpful, with no significant differences between them.

Thirty-seven percent of mothers did not take up treatment despite being screened as probably depressed and effective treatments being available. Although some of the reported

Table 4

Difficulty coping since the birth by original screening classification.

\begin{tabular}{llll}
\hline & $\begin{array}{l}\text { Screened } \\
\text { positive }\end{array}$ & & $\begin{array}{l}\text { Screened } \\
\text { negative }\end{array}$ \\
\cline { 2 - 2 } & $\mathrm{N}=97^{*}(\%)$ & $\mathrm{N}=101(\%)$ \\
\hline Coped okay & $10(10.3)$ & & $21(20.8)$ \\
Difficulties coping - less than 2 weeks & $54(55.7)$ & & $56(55.4)$ \\
Difficulties coping - 2 weeks or more & $33(34.0)$ & & $24(23.8)$ \\
\hline
\end{tabular}

\footnotetext{
* Missing data for 1 participant.
}

Table 5

Type of treatment received in first 2 years and perceived helpfulness $\mathrm{N}=83$ (includes screened positive and negative mothers).

\begin{tabular}{|c|c|c|}
\hline Type of treatment received & $\mathrm{N}(\%)$ & $\begin{array}{l}\text { Perceived helpfulness of } \\
\text { treatment }^{1}\end{array}$ \\
\hline $\begin{array}{l}\text { General counselling } \\
\text { (e.g. telephone; GP) }\end{array}$ & $58(69.9 \%)$ & $73.2 \%^{2}$ \\
\hline Medication $^{\mathrm{A}}$ & $32(38.6 \%)$ & $76.6 \%^{3}$ \\
\hline $\begin{array}{l}\text { Structured counselling } \\
\quad(\mathrm{CBT}, \mathrm{IPT} \text {, group, couple })^{\mathrm{B}}\end{array}$ & $18(21.7 \%)$ & $78.8 \%$ \\
\hline Self-help & $16(19.3 \%)$ & $93 \%$ \\
\hline Complementary therapy & $11(13.3 \%)$ & $50 \%$ \\
\hline Consumer support service & $4(4.8 \%)$ & $50 \%$ \\
\hline Inpatient unit & $2(2 \%)$ & $50 \%$ \\
\hline
\end{tabular}

Note: participants may have received more than one type of treatment hence $\%$ totals more than $100 \%$.

$1 \%$ rating the treatment as 'very helpful' or 'helpful.'

$211 \%$ reported it made them worse.

3 3\% reported it made them worse.

A Significantly more women in the Initial 'screen positive' group received this treatment.

B $\mathrm{CBT}=$ cognitive behavioural therapy, IPT = interpersonal psychotherapy, group or couple counselling).

obstacles were system and practical barriers, the most significant factor was the mothers' own reluctance (see Table 6). For instance, more than half cited a preference for using their own resources to deal with their difficulties (53.5\%). Many reported they found it difficult to confide in others (46.5\%) or accept they had difficulties (30\%). One-third simply chose not to get help, despite being aware of the available services. Furthermore, the reasons women don't seek help were the same for those with short or long durations of difficulties. Interestingly, looking at those women who screened positive but did not receive treatment, we found no meaningful $(\phi=.07)$ or statistical $(p=n s)$ difference in outcome for those who preferred to sort things out themselves compared to those who cited other obstacles (46.7\% vs. $38.5 \%$, classified probably depressed).

Table 6

Obstacles to accessing treatment and support $(\mathrm{N}=43)$.

\begin{tabular}{lll}
\hline & \multicolumn{2}{l}{ Responses } \\
\cline { 2 - 3 } & $\mathrm{N}$ & Percent of women \\
\hline Preferred to sort things out myself & 23 & $53.5 \%$ \\
Found it difficult to tell others & 20 & $46.5 \%$ \\
Chose not to get help & 14 & $32.6 \%$ \\
Hard to accept I had difficulties & 13 & $30.2 \%$ \\
No childcare & 9 & $20.9 \%$ \\
Normalised symptoms & 9 & $20.9 \%$ \\
Unaware of services & 8 & $18.6 \%$ \\
Concerned about side effects & 8 & $18.6 \%$ \\
Didn't get around to it & 7 & $16.3 \%$ \\
Aware but couldn't get help & 6 & $14.0 \%$ \\
No transport & 1 & $2.3 \%$ \\
\hline
\end{tabular}

Note: $\mathrm{N}$ tallies to more than the 43 women, and more than $100 \%$, as more than one reason could be given by each woman. 


\subsection{Relationships with infant and partner}

Mothers who were 'never depressed' had significantly better scores on the infant bonding measure compared to those with persistent depression $(\mathrm{t}(59)=-2.142, p=.036$, $\mathrm{d}=0.46)$ and mothers classified as 'new cases' of depression at 2 years $(\mathrm{t}(12)=-2.688, p=.019, \mathrm{~d}=1.11)$. Furthermore, women who were depressed at 2 years postpartum were more likely to report they had separated or divorced from their partner during the follow-up period compared to those who were classified 'unlikely to be depressed' (13\% vs. 3.4\%; $\left.\chi^{2}[1, \mathrm{~N}=199]=6.29, p=.012 ; \phi=.18\right)$. Of the women who were in still in a relationship, 'screened positive' women were more likely to report the relationship with the baby's father to be poor compared to screened negative women (21.8\% vs. $6.1 \%$, respectively; $\chi^{2}[1, \mathrm{~N}=185]=9.74, p=.002, \phi=.23$ ). Likewise, mothers with elevated EPDS scores at 2 years were significantly worse off on this measure of relationship quality than women scoring in the unlikely to be depressed range (30.4\% vs. $7.9 \%$, respectively; $\chi^{2}[1, \mathrm{~N}=185]=15.0 p<.001$, $\phi=.28)$.

\section{Discussion}

Mothers who 'screened positive' for depression by the original screening program were doing significantly worse than 'screened negative' mothers both in terms of mean depression scores and the proportions categorised as probably depressed at 2 years postpartum. This study found approximately $40 \%$ of screened positive women were probably depressed again at 2 years, indicating the possible presence of persistent or recurrent symptoms, compared to $11 \%$ of women who originally screened negative. Those women who were detected at just one time point (pregnancy or $6-8$ weeks postnatal) had a 1 in 2.5 chance of being classified as probably depressed (or not coping) at 2 years. Furthermore, they were approximately three times as likely to have moderate-severe depressive symptomatology at 2 years compared to women who had screened negative. There is some indication that being depressed at both time points is associated with a doubling of the risk for being probably depressed at 2 years. However, the likelihood of being probably depressed at 2 years seems unaffected by whether or not women sought treatment.

Disruptions in the mother-infant bond are of serious concern because of their implication in the development of complex relationship problems, including child neglect and abuse (Brockington et al., 2001). In this study, mothers with persistent depression and those who were classified as 'new cases' of depression at 2 years had significantly poorer bonding with their toddler. In other words, current depression symptoms, not a history of symptoms, were associated with poorer maternal-infant bonding at the follow-up period. One of the limitations of the current study is the use of a selfreport measure of mother-infant outcome. It is possible that depressed mothers perceive their bonding in a more negative way, however, a recent longitudinal study of PND and maternal bonding found evidence to the contrary (Moehler et al., 2006). The current study also found an association between PND and poorer partner relationships in the long term. While single motherhood and poor partner support are well documented risk factors for PND, the trend for relationship difficulties seems to continue over time for mothers affected by PND. Women who were depressed at 2 years were more likely to report a separation or divorce during the follow-up period and more likely to report the quality of their partner relationship as poorer than the control group, a finding consistent with prior research (Wallace and Gotlib, 1990; Carro et al., 1993; Beck, 2001; Patel et al., 2002; McMahon et al., 2008).

An interesting finding of the study was the difference in work status between the two conditions with fewer originally depressed mothers returning to employment. Evidence from previous research into work characteristics and PND have returned mixed findings with some reporting that employment is a protective factor against depression (Mayberry et al., 2007; Walker, 1989) and others finding no differences in work status between depressed and non depressed mothers (Campbell et al., 1992). While this study was not designed to determine the direction of the association, it is possible that the relationship works both ways. For instance, unemployment may raise a woman's risk of developing chronic depression due to financial stress, inequitable distribution of household roles or lack of adult company. It is also possible that the symptoms of depression result in impairments in social and occupational functioning, making it more difficult to return to the workforce. Poor maternal education has also been implicated in the development of chronic depression (McMahon et al., 2005) and it may be that other factors may operate as risk factors or mediators of outcome. Further research is needed to explore the relationship between chronic maternal depression and employment.

Despite the fact that maternal depression was detected by health professionals in the screening program and effective treatments were available, $37 \%$ of depressed mothers did not access professional treatment. Consistent with prior research, the most significant obstacles to treatment were the mothers themselves (Russell, 2006). Specifically, mothers reported a preference for using their own resources and the stigma of having a mental health problem as significant barriers. It is possible that many of the usual system barriers are being addressed by screening initiatives. Clearly, more work is needed to address women's fears and reluctance to disclose their problems whilst encouraging them to take up treatment, especially those at risk of persistent depression. It has been shown that mothers are more likely to accept professional advice when it is in agreement with her perception of her depression and its causes (McIntosh, 1993). Research could focus on whether more thorough assessment of 'perception of causes' leads to increased acceptance of professional help. Novel initiatives are already underway to address ways of engaging women in treatment targeting some of the most vulnerable groups (Grote et al., 2004). On the other hand, the majority of screened positive women who used their own resources were very satisfied with this, thus, we should recognise that not all women with emotional difficulties will necessarily need or want professional help.

We could find few comparable long-term studies of screening programs that examine the course of depression in mothers who screen positive, although the findings from the PoNDER trial are noteworthy (Morrell et al., 2009a,b). In 
the UK, Morrell and colleagues conducted a cluster, randomised controlled trial examining the short and long-term outcomes for at-risk mothers ( more). Health visitors were trained to systematically screen and identify mothers with depression as well as provide psychological treatment (cognitive behavioural counselling or person-centred counselling). Mothers who received the interventions were less likely than women in the Usual Care condition to have an elevated score at 6 months postpartum (34\% vs. 46\%, respectively) and their gains were maintained at 1 year postpartum. Direct comparisons are hindered by the fact that the PoNDER trial used a different follow-up period ( 1 vs. 2 years postpartum), a lower EPDS cut-off score (not the validated cut-off score; c.f. Matthey et al., 2006) and significant data were missing at the long-term follow-up. Nevertheless, we note our finding of $40 \%$ of screened positive mothers with elevated EPDS scores at 2 years is similar to their finding of $41.9 \%$ for Usual Care mothers at 1 year postpartum. It would appear that programs obtain superior results when they integrate screening, diagnostic assessment and access to evidence-based treatments compared to programs that require mothers to follow-up referral options. Stepped care approaches, which aim to overcome some of the barriers to treatment and improve access to specialist mental health services, also show good promise (Baker-Ericzen et al., 2008; Gjerdingen et al., 2008, 2009; Miller et al., 2009). Future research is needed, however, to establish the clinical and cost effectiveness of stepped care programs with this population.

The implications of this study for screening programs are worth noting. Mothers who were detected as depressed on two screening occasions could be identified as a high priority for follow-up given their risk for a negative mental health trajectory. Furthermore, our two findings: that a significant number of women who reported difficulties coping, feeling stressed or unhappy were not detected by the screening program and the number of 'new cases' of depression at 2 years postpartum, point to the need for ongoing evaluation of women's mental health. Indeed, the beyondblue National PND program now recommends three postnatal assessment points: 6-8 weeks, 3-4 months and 6-8 months (Buist et al., 2008).

\section{Limitations}

There are a number of limitations of this study. In this mailed survey of participants, we relied exclusively on selfreport questionnaires for determining the presence of depression symptoms. The study could have been strengthened by the use of structured interviews to diagnose depression and behavioural measures to assess mother-infant attachment quality. Caution should be used when interpreting the results for the quality of the partner relationship as the one-item question used in this study has not been validated. Some of the data on treatment were collected retrospectively using a self-report measure. As such there is a risk that women may not accurately recall events or their responses may be influenced by social desirability. The data could have been strengthened by the inclusion of detailed information on dose, frequency and length of treatment or support using case records. Unfortunately, this was not feasible in a widespread screening program where women access help from a diverse range of service providers. On the other hand, one of the strengths of the treatment data was that it was not limited solely to professional treatment, encompassing a diverse range of options for help and support, including complementary therapies, self help and consumer support.

\section{Conclusions}

$40 \%$ of 'screened positive' women and $11 \%$ of 'screened negative' women had elevated depression symptoms at the two-year follow-up. These women also experienced more problematic partner relationships and poorer infant bonding. The most notable finding was a more than four fold risk for probable depression or difficulty coping at 2 years postpartum for mothers detected as depressed compared to the not depressed cohort. Moreover, there appears to be a double dose effect: women who screened positive on two occasions (pregnancy and 6 weeks postpartum) were almost twice as likely to be probably depressed at 2 years postpartum, compared with those who screened positive on only one occasion. The majority of depressed women received some type of treatment (63\%), and whichever types of professional treatments are received, about two-thirds of the time they are rated as helpful. More than half of the untreated mothers preferred to use their own resources rather than seek professional help. We could find no evidence that untreated mothers were worse off in the long term compared to those who accessed treatment. The stigma of having a mental health problem, difficulties disclosing it to others and accepting offers of help were also identified as major barriers to treatment.

Programs that aim to screen, diagnose and treat postnatal depression have potential benefits for women and their families. This study points to some of the ways programs can better assist women at high risk of persistent or recurrent depressive episodes. Perinatal depression screening and assessment needs to occur frequently enough to ensure women who develop problems later in the postpartum are not missed. Programs need to ensure that women do not drop-out, especially those who are identified as probably depressed on two occasions. There is also need to investigate emerging new approaches that address women's reluctance to accept treatment in 'real world' settings. Bridging the gap between engaging depressed mothers and the pathways to recovery remains a public health challenge.

\section{Role of funding source}

This study was supported by The Canberra Hospital Private Practice fund at the hospital where the first and third authors work. The funding agency played no further role in any aspect of the study including: its design; in the collection, analysis and interpretation of data; in the writing of the report; and in the decision to submit the paper for publication.

\section{Conflicts of interest}

The authors declare that they have no conflicts of interest.

\section{Acknowledgements}

The authors would like to acknowledge The Canberra Hospital Private Practice fund for funding the current study and beyondblue: the national depression initiative for funding the original study. We also acknowledge the valuable contribution of the many mothers and health professionals that participated in the screening program. 


\section{References}

Armstrong, S., Small, R., 2007. Screening for postnatal depression: not a simple task. Aust. N. Z. J. Public Health 31, 57-61.

Austin, M.P., Hadzi-Pavlovic, D., Saint, K., Parker, G., 2005. Antenatal screening for the prediction of postnatal depression: validation of a psychosocial Pregnancy Risk Questionnaire. Acta Psychiatr. Scand. 112, 310-317.

Baker-Ericzen, M.J., Mueggenborg, M.G., Hartigan, P., Howard, N., Wilke, T., 2008. Partnership for women's health: a new-age collaborative program for addressing maternal depression in the postpartum period. Fam. Syst. Health 26, 30-43.

Beck, C.T., 2001. Predictors of postpartum depression: an update. Nurs. Res. 50, 275-285.

Beck, C.T., Gable, R.K., 2001. Comparative analysis of the performance of the Postpartum Depression Screening Scale with two other depression instruments. Nurs. Res. 50, 242-250.

Beck, A.T., Steer, R.A., Garbin, M.G., 1988. Psychometric properties of the Beck Depression Inventory: twenty-five years of evaluation. Clin. Psychol. Rev. 8, 77-100.

Beck, A.T., Steer, R.A., Brown, G.K., 1996. Manual for the Beck Depression Inventory-II. Psychological Corporation, San Antonio.

Beeghly, M., Weinberg, M.K., Olson, K.L., Kernan, H., Riley, J., Tronick, E.Z., 2002. Stability and change in level of maternal depressive symptomatology during the first postpartum year. J. Affect. Disord. 71, 169-180.

Boath, E.H., Pryce, A.J., Cox, J.L., 1998. Postnatal depression: the impact on the family. J. Reprod. Infant. Psychol. 16, 103-199.

Brockington, I.F., Oates, J., George, S., Turner, D., Vostanis, P., Sullivan, M., Loh, C., Murdoch, C., 2001. A screening questionnaire for mother-infant bonding disorders. Arch. Womens Ment. Health 3, 133-140.

Brooks, J., Nathan, E., Speelman, C., Swalm, D., Jacques, A., Doherty, D., 2009. Tailoring screening protocols for perinatal depression: prevalence of high risk across obstetric services in Western Australia. Arch. Womens Ment. Health 12, 105-112.

Buist, A.E., Bilszta, J., Milgrom, J., Condon, J., Speelman, C., Hayes, B., Barnett, B., Ellwood, D., 2005. The beyondblue National Postnatal Depression Program. Prevention and Early Intervention 2001-2005 Final Report. Volume 1: National Screening Program. beyondblue - The Depression Initiative, Melbourn.

Buist, A., Condon, J., Brooks, J., Speelman, C., Milgrom, J., Hayes, B., Ellwood, D., Barnett, B., Kowalenko, N., Matthey, S., Austin, M.-P., Bilszta, J., 2006. Acceptability of routine screening for perinatal depression. J. Affect. Disord. 93, 233-237.

Buist, A.E., Austin, M.P., Hayes, B.A., Speelman, C., Bilszta, J.L., Gemmill, A.W. Brooks, J., Ellwood, D., Milgrom, J., 2008. Postnatal mental health of women giving birth in Australia 2002-2004: findings from the beyondblue National Postnatal Depression Program. Aust. N. Z. J. Psychiatry 42, 66-73.

Campbell, S.B., Cohn, J.F., 1997. The timing and chronicity of postpartum depression: implications for infant development. In: Murray, L., Cooper P.J. (Eds.), Postpartum Depression and Child Development. Guilford, New York, pp. 165-197

Campbell, S.B., Cohn, J.F., Flanagan, C., Popper, S., et al., 1992. Course and correlates of postpartum depression during the transition to parenthood. Dev. Psychopathol. 4, 29-47.

Carro, M.G., Grant, K.E., Gotlib, I.H., Compas, B.E., 1993. Postpartum depression and child development: an investigation of mothers and fathers as sources of risk and resilience. Dev. Psychopathol. 5 , 567-579.

Chew-Graham, C.A., Sharp, D., Chamberlain, E., Folkes, L., Turner, K.M., 2009. Disclosure of symptoms of postnatal depression, the perspectives of health professionals and women: a qualitative study. B.M.C. Fam. Pract. $10,7$.

Cooper, P.J., Murray, L., 1995. Course and recurrence of postnatal depression. Evidence for the specificity of the diagnostic concept. Br. J. Psychiatry 166, 191-195.

Cornish, A.M., McMahon, C.A., Ungerer, J.A., Barnett, B., Kowalenko, N., Tennant, C., 2006. Maternal depression and the experience of parenting in the second postnatal year. J. Reprod. Infant. Psychol. 24, $121-132$.

Cox, J.L., Holden, J.M., Sagovsky, R., 1987. Detection of postnatal depression. Development of the 10-item Edinburgh Postnatal Depression Scale. Br. J. Psychiatry 150, 782-786.

Cox, J.L., Chapman, G., Murray, D., Jones, P., 1996. Validation of the Edinburgh Postnatal Depression Scale (EPDS) in non-postnatal women. J. Affect. Disord. 39, 185-189.

Dennis, C.L., Chung-Lee, L., 2006. Postpartum depression help-seeking barriers and maternal treatment preferences: a qualitative systematic review. Birth 33, 323-331.
Dipietro, J.A., Costigan, K.A., Sipsma, H.L., 2008. Continuity in self-report measures of maternal anxiety, stress, and depressive symptoms from pregnancy through two years postpartum. J. Psychosom. Obstet. Gynaecol. 29, 115-124.

Evins, G.G., Theofrastous, J.P., Galvin, S.L., 2000. Postpartum depression: a comparison of screening and routine clinical evaluation. Am. J. Obstet. Gynecol. 182, 1080-1082.

Gjerdingen, D., Katon, W., Rich, D.E., 2008. Stepped care treatment of postpartum depression: a primary care-based management model. Womens Health Issues 18, 44-52.

Gjerdingen, D., Crow, S., McGovern, P., Miner, M., Center, B., 2009. Stepped care treatment of postpartum depression: impact on treatment, health and work outcomes. J. Am. Board Fam. Med. 22, 473-482.

Grote, N.K., Bledsoe, S.E., Swartz, H.A., Frank, E., 2004. Culturally relevant psychotherapy for perinatal depression in low-income Ob/Gyn patients. Clin. Soc. Work J. 32, 327-347.

Heron, J., O'Connor, T.G., Evans, J., Golding, J., Glover, V., 2004. The course of anxiety and depression through pregnancy and the postpartum in a community sample. J. Affect. Disord. 80, 65-73.

Hewitt, C., Gilbody, S., 2009. Is it clinically and cost effective to screen for postnatal depression: a systematic review of controlled clinical trials and economic evidence. B.J.O.G. 116, 1019-1027.

Kim, J.J., La Porte, L.M., Corcoran, M., et al., 2010. Barriers to mental health treatment among obstetric patients at risk for depression. Am. J. Obstet. Gynecol. 202, 312.e1-5.

Kline, R.B., 2004. Beyond Significance Testing: Reforming Data Analysis Methods in Behavioral Research. American Psychological Association, Washington DC.

Lovestone, S., Kumar, R., 1993. Postnatal psychiatric illness: the impact on partners. Br. J. Psychiatry 163, 210-216.

Matthey, S., 2009. Women's perceptions of the causes of their postnatal distress: development of the reasons for postnatal distress checklist. Depress. Anxiety 26, 938-948.

Matthey, S., Henshaw, C., Elliott, S., Barnett, B., 2006. Variability in use of cutoff scores and formats on the Edinburgh Postnatal Depression Scale: implications for clinical and research practice. Arch. Womens Ment. Health 9, 309-315.

Mayberry, L.J., Horowitz, J.A., Declercq, E., 2007. Depression symptom prevalence and demographic risk factors among U.S. women during the first 2 years postpartum. J. Obstet. Gynecol. Neonatal Nurs. 36, 542-549.

McIntosh, J., 1993. Postpartum depression: women's help-seeking behaviour and perceptions of cause. J. Adv. Nurs. 18, 178-184.

McMahon, C., Barnett, B., Kowalenko, N., Tennant, C., 2005. Psychological factors associated with persistent postnatal depression: past and current relationships, defence styles and the mediating role of insecure attachment style. J. Affect. Disord. 84, 15-24.

McMahon, C., Trapolini, T., Barnett, B., 2008. Maternal state of mind regarding attachment predicts persistence of postnatal depression in the preschool years. J. Affect. Disord. 107, 199-203.

Milgrom, J., Ericksen, J., Negri, L., Gemmill, A.W., 2005. Screening for postnatal depression in routine primary care: properties of the Edinburgh Postnatal Depression Scale in an Australian sample. Aust. N. Z. J. Psychiatry 39, 833-839.

Miller, L., Shade, M., Vasireddy, V., 2009. Beyond screening: assessment of perinatal depression in a perinatal care setting. Arch. Womens Ment. Health 12, 329-334.

Moehler, E., Brunner, R., Wiebel, A., Reck, C., Resch, F., 2006. Maternal depressive symptoms in the postnatal period are associated with long-term impairment of mother-child bonding. Arch. Womens Ment. Health 9, 273-278.

Monti, F., Agostini, F., Marano, G., Lupi, F., 2008. The course of maternal depressive symptomatology during the first 18 months postpartum in an Italian sample. Arch. Womens Ment. Health 11, 231-238.

Morrell, C.J., Slade, P., Warner, R., Paley, G., Dixon, S., Walters, S.J., et al., 2009a. Clinical effectiveness of health visitor training in psychologically informed approaches for depression in postnatal women: pragmatic cluster randomised trial in primary care. BMJ 15, 338:a3045.

Morrell, C.J., Warner, R., Slade, P., Dixon, S., Walters, S., Paley, G., Brugha, T., 2009b. Psychological interventions for postnatal depression: cluster randomised trial and economic evaluation. The PoNDER trial. Health Technol. Assess. 13, 1-153.

Muller, M.E., 1994. A questionnaire to measure mother-infant interaction. J. Nurs. Meas. 2, 129-141.

Murray, L., 1992. The impact of postnatal depression on infant development. J. Child Psychol. Psychiatry 33, 543-561.

O'Hara, M.W., Neunaber, D.J., Zekoski, E.M., 1984. Prospective study of postpartum depression: prevalence, course, and predictive factors. J. Abnorm. Psychol. 93, 158-171.

Patel, V., Rodrigues, M., DeSouza, N., 2002. Gender, poverty, and postnatal depression: a study of mothers in Goa, India. Am. J. Psychiatry 159, 43-47. 
Paulden, M., Palmer, S., Hewitt, C., Gilbody, S., 2009. Screening for postnatal depression in primary care: cost effectiveness analysis. BMJ 339, b5203.

Philipps, L.H., O'Hara, M.W., 1991. Prospective study of postpartum depression: 4 1/2-year follow-up of women and children. J. Abnorm. Psychol. 100, 151-155.

Rubertsson, C., Wickberg, B., Gustavsson, P., Radestad, I., 2005. Depressive symptoms in early pregnancy, two months and one year postpartumprevalence and psychosocial risk factors in a national Swedish sample. Arch. Womens Ment. Health 8, 97-104.

Russell, S., 2006. Barriers to care in postnatal depression. Community Pract. 79, 110-111.

Shakespeare, J., 2002. Evaluation of screening for postnatal depression against the NSC criteria www.library.nhs.uk/specialistlibrarysearch/ download.aspx? resid=60971 Date accessed 5th April, 2008

Smith, M.V., Shao, L., Howell, H., Wang, H., Poschman, K., Yonkers, K.A., 2009. Success of mental health referral among pregnant and postpartum women with psychiatric distress. Gen. Hosp. Psychiatry 31, 155-162.

Thio, I.M., Oakley Browne, M.A., Coverdale, J.H., Argyle, N., 2006. Postnatal depressive symptoms go largely untreated: a probability study in urban New Zealand. Soc. Psychiatry Psychiatr. Epidemiol. 41, 814-818.

Tronick, E.Z., Weinberg, M.K., 1997. Depressed mothers and infants: failure to form dyadic states of consciousness. In: Murray, L., Cooper, P. (Eds.), Postpartum Depression and Child Development. Guilford Press, New York, pp. 54-81.
Walker, L.O., 1989. Stress process among mothers of infants: preliminary model testing. Nurs. Res. 38, 10-16.

Wallace, P.M., Gotlib, I.H., 1990. Marital adjustment during the transition to parenthood: stability and predictors of change. J. Marriage Fam. Living 52, 21-29.

Webster, J., Linnane, J., Roberts, J., Starrenburg, S., Hinson, J., Dibley, L., 2003. IDentify, Educate and Alert (IDEA) trial: an intervention to reduce postnatal depression. B.J.O.G. 110, 842-846.

Whiffen, V.E., Gotlib, I.H., 1993. Comparison of postpartum and nonpostpartum depression: clinical presentation, psychiatric history, and psychosocial functioning. J. Consult. Clin. Psychol. 61, 485-494.

Woolhouse, H., Brown, S., Krastev, A., Perlen, S., Gunn, J., 2009. Seeking help for anxiety and depression after childbirth: results of the Maternal Health Study. Arch. Womens Ment. Health 12, 75-83.

Yonkers, K.A., Smith, M.V., Lin, H., Howell, H.B., Shao, L., Rosenheck, R.A., 2009. Depression screening of perinatal women: an evaluation of the healthy start depression initiative. Psych. Ser. 60, 322-328. 